\title{
Building Leadership in Rural Women through Skill Training
}

\author{
S.S. Bansode* , S.S. Kale and P.M. Jogdand \\ PGI ABM Chakur, Vasantrao Naik Marathwada Krishi Vidyapeeth, Parbhani (MH), India \\ *Corresponding author
}

\section{A B S T R A C T}

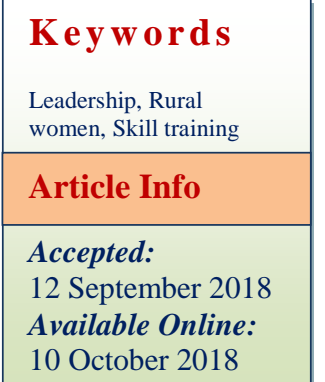

\section{Introduction}

In most developing countries, women perform a large part (and often most) of the agricultural work, and they produce most of the world's food crops. However, their productivity, as well as the state of food security more widely, is constrained by gender-specific barriers in addition to those faced by all smallholder farmers. Without a significant investment in improving the livelihoods, assets and decisionmaking capacity of rural women, it is unlikely that the Millennium Development Goals to reduce hunger will be achieved. At national and global levels, women's voices are weak, largely because of their minimal presence in leadership roles of rural organizations, the challenges of being treated as 'token' women rather than equally with male leaders and, in some cases, the limited ability of the few women leaders at the national level to effectively represent the needs of women at the grass-roots level. There is also a difference between women's representation in womenonly groups and mixed-sex groups. Women's groups tend to be confined to the local level, often organized around economic activities. In mixed organizations, while women may be well represented as members, there are generally few in leadership positions, and this is even more the case at national and international levels. Therefore, there is a gap between women's contribution to agricultural production, marketing and rural livelihoods, and their voice in making decisions that affect them, their livelihoods and their communities.

Preparing women members of producer organizations to be leaders and change agents in their organizations - Sensitization of women 
leaders of producer organizations on topics including gender relations, self-awareness, leadership and accountability, negotiation and conflict management, advocacy and lobbying, communication and adult education methodology and agricultural and natural resources management policies as they affect women - Exchange visits to expose women at the grass-roots level to new role models Mentoring and backstopping of women leaders at the grass-roots level.

Fostering enabling environments for gender sensitivity and women's leadership - Training and sensitization for men in producer organizations and related institutions to support rural women's leadership.

Promoting the capacity for advocacy and involvement of women farmers' organization leaders in national, regional and global policy processes - Training for women leaders on advocacy tools and methods - Supporting the participation of representative women leaders in major regional and global policy dialogues.

Creating sustainable networks of women leaders to promote investments and partnerships to make agriculture more responsive to the needs of poor women farmers - Supporting consultations between rural women and decision makers - Promoting the use of media communications to influence public perceptions of women's economic role and women as leaders - Networking and building partnerships with donors and other organizations already supporting women leaders - Supporting rural women's participation in global policy forums and events.

\section{Materials and Methods}

\section{Factors influencing women entrepreneurs}

Building Confidence
Developing risk taking ability

Economic independence

Establishing their own creative idea

Establishing their own Motivation identity

Equal status in society

Greater freedom and mobility

\section{Build leadership in rural women}

Female leaders are commonly described as encouraging, supporting and sharing power and information with others. Female leaders are also described to give more feedback and recognition to their employees and more socially sensitive than their male colleagues. In motivation these are the essential qualities that leaders need when they want to improve their employees ${ }^{\text {ee }}$ motivation and job satisfaction. Leaders today want know how their leadership style affects to motivation that is, ultimately to the delivery of business performance.

\section{Challenges faced by rural women in taking leadership roles}

Constraints were: Balancing women's productive/household responsibilities and outside/community/professional work. Almost all women, both rural and professional stated that balancing household and outside work was one of the key issues that hindered them from taking up responsibilities or participating meaningfully. There is limited understanding, support and encouragement at the household level for women to engage in these activities outside the home. There is a limited recognition and value of women's "reproductive role". Though workloads have been reduced with the introduction of appropriate time saving technologies, the sharing of household work by other household members is still not commonly done. Time constraints and missed opportunities: trainings, key meetings for decisions are usually held during the time when women are 
busy with their household work. Restrictions at family level and household responsibility were observed as major challenges. Limited skills and limited access to technologies was another challenge. Though the road networks/infrastructures have improved, women are not able to make optimum use of these.

For example, several rural women stated that they were mostly late in reaching the local/district level offices or had to leave early before the decisions were made in the meetings to be home on time to cook dinner. Limited networks and systematic exclusion of women: Women have limited networks (particularly to sources/platforms related to resources and traditional/mainstream networks).

They are unable to actively participate in even those few networks that they are linked to, due to lack of time, limited education and skills, infrastructure constraints, culture etc.

\section{Results and Discussion}

Self-awareness: One of the most important outcomes of the training was the increase in self-awareness among the trained women leaders and their respective group members, particularly on issues of exclusion and discrimination within households and at community/institutional levels.

Women leaders said that they were able to identify and understand the different forms of exclusion and discrimination which helped them to better deal with it.

Resource mobilization and ability to make demands: The training helped women leaders and their groups to be proactive and access local level resources allocated for women as well as other resources for their benefit. Women were found to be taking more interest in community level activities. As a result they became more informed and were able to actively participate, voice their opinions and make demand for services and resources.

\section{Interpretation}

The above pie-chart shows that $6 \%$ women's reason behind the backwardness is due to not getting family support, $17 \%$ due to education and $17 \%$ due to poverty.

\section{Interpretation}

The above graph shows that the women starts business after training Home Business 33\% retail shop $27 \%$, stationary $17 \%$ and other $23 \%$.

\section{Interpretation}

The above graph shows that the percentage of improvement in women remove from fear is $17 \%$, build self-confidence is $33 \%$, doing business is $50 \%$.

\section{Suggestions}

Women's economic empowerment Support

Target young women in youth entrepreneurship initiatives.

Equal voice and decision-making Adopt a long-term approach.

Create opportunities for rural women to participate in mixed and women-only farmers' organizations and in both formal and informal ones.

Facilitate women's increased representation and strengthen gender relations.

Support behavioral change in the home to unlock women's leadership potential outside it. 
Reason behind backwardness of women

\begin{tabular}{|l|l|l|}
\hline PARAMETER & RESPONDENT & PERCENTAGE \\
\hline POVERTY & 5 & $17 \%$ \\
\hline EDUCATION & 5 & $17 \%$ \\
\hline FAMILY SUPPORT & 20 & $66 \%$ \\
\hline TOTAL & 30 & 100
\end{tabular}

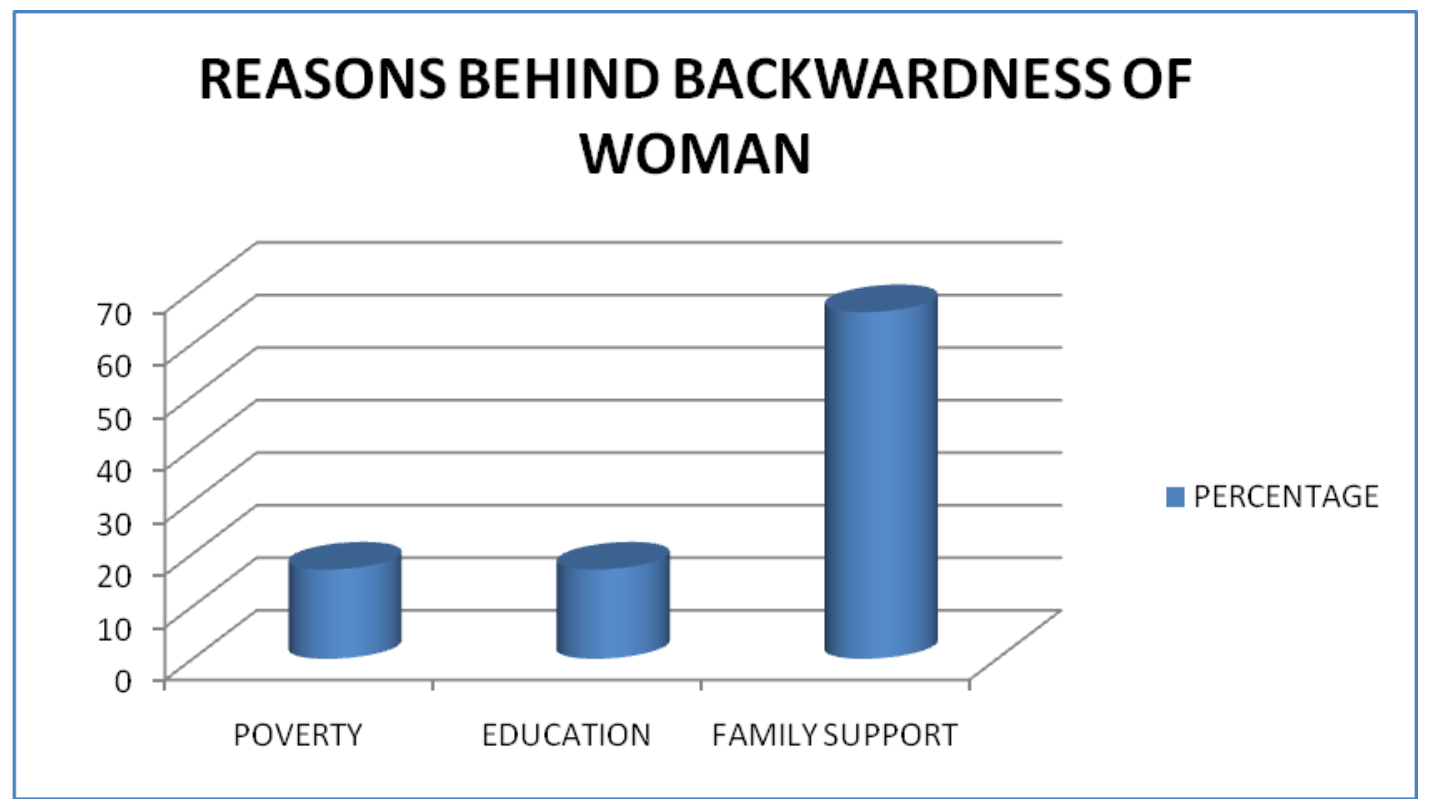

Business started after training

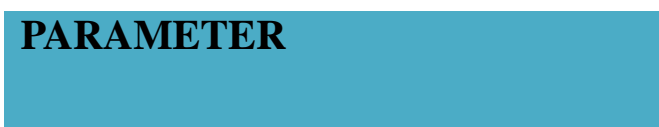

RESPONDENT

Home Business

\section{Retail Shop}

\section{Stationary}

Other

TOTAL
10

\begin{tabular}{|l|}
\hline 10 \\
\hline 05 \\
\hline 08 \\
\hline 07 \\
\hline 30 \\
\hline
\end{tabular}

$33 \%$

$17 \%$

$27 \%$

$23 \%$

100 


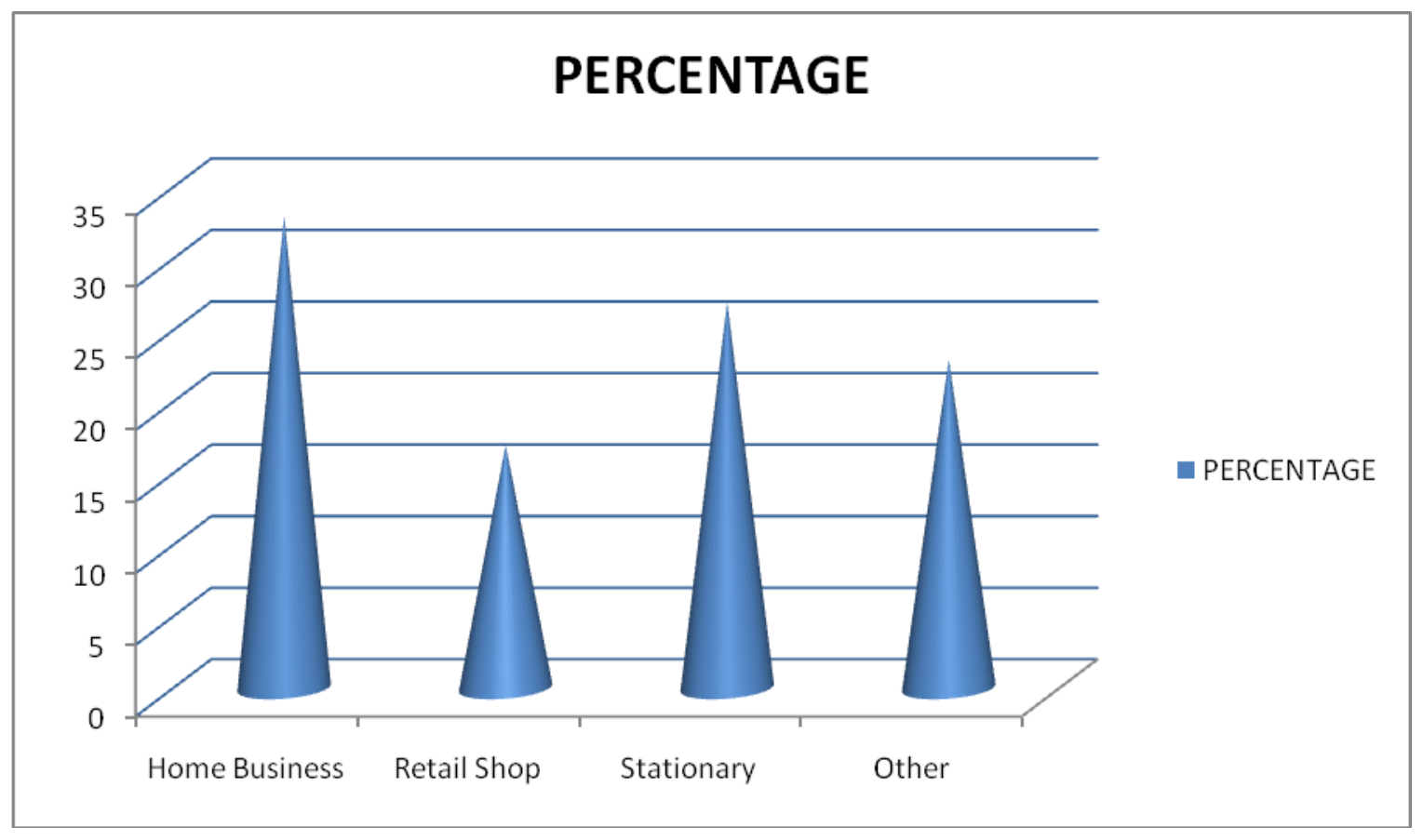

Improvement of women

\begin{tabular}{|l|l|l|}
\hline PARAMETER & RESPONDENT & PERCENTAGE \\
\hline REMOVE FEAR & $\mathbf{5}$ & $\mathbf{1 7} \%$ \\
\hline SELF CONFIDENCE & $\mathbf{1 0}$ & $\mathbf{3 3} \%$ \\
\hline DOING BUSINESS & 15 & $\mathbf{5 0} \%$ \\
\hline TOTAL & $\mathbf{3 0}$ & $\mathbf{1 0 0}$ \\
\hline
\end{tabular}

\section{RESPONDENT}

REMOVE FEAR $\square$ SELF CONFIDENCE $\square$ DOING BUSINESS

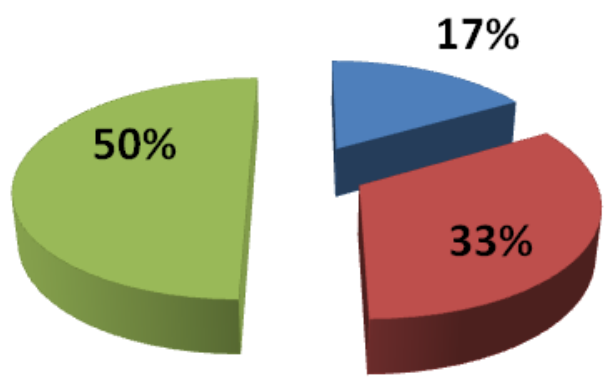


Ensure that women's leadership courses include an appropriate mix of skills.

Support more enabling policy frameworks at the national and local levels.

This study examined the characteristics of successful women in leadership positions, the most common barriers that they experience in today's workplace, the negative impact of those barriers on their work and well-being, and their leadership style and performance. The variables examined in this study link together to form a comprehensive story about women in leadership. Personality either enables women or hinders them from overcoming the challenges and stereotype threat they will inevitably face in leadership positions to perform capably in their leadership roles and utilize effective leadership techniques.

\section{References}

Human Resource Management - Biswajeet Pattanayak

Organization records

Research methodology: methods \& Techniques- C. R. Kothari.

SSEN annual report.

www.google.com

www.ssen.org.in

www.ssenindia.com

www.sspindia.org

www.wikipedia.org

\section{How to cite this article:}

Bansode, S.S., S.S. Kale and Jogdand, P.M. 2018. Building Leadership in Rural Women through Skill Training. Int.J.Curr.Microbiol.App.Sci. 7(10): 1605-1610.

doi: https://doi.org/10.20546/ijcmas.2018.710.181 